\title{
RANCANGAN SISTEM INFORMASI RIWAYAT PERBAIKAN RECEIVER BERBASIS WEB PADA PT MNC VISION
}

\author{
Jenie Sundari ${ }^{1}$, Abdul Azis ${ }^{2}$ \\ ${ }^{12}$ STMIK Nusa Mandiri Jakarta, Jl. Kramat Raya No. 18 Jakarta Pusat \\ Jurusan Teknik Informatika, Jakarta \\ Email : ${ }^{1}$ Jenie.jni@nusamandiri.ac.id, ${ }^{2}$ Azis99768@gmail.com
}

\begin{abstract}
PT. MNC VISION is a company engaged in satellite tv. Problems in dealing with this company is, not the existence of the sikronisasi history of the condition of the receiver. Where the receiver is used as a means of capturing a signal for satellite tv. This receiver at pinjamkan party company to the customers. Logging with the manual for this receiver, so that in the event of damage or repairs on the receiver, the receiver does not condition history quickly note the results. This author makes issue of architecture history information system improvements to receivers using the method waterfall. With this method, the author analyzes the system requirements, designing the look of the web, designing the application and test the success of the system. The result is, in the form of web-based information system where data damage receiver can be directly input and known problems of the damage, expected to speed up the report the condition of the receiver, allowing parties to repair damage in handling receiver.
\end{abstract}

Keywords : $\quad$ inventory, web, receiver, waterfall

\begin{abstract}
ABSTRAK
PT. MNC VISION adalah perusahaan yang bergerak dibidang televise satelit. Masalah yang di hadapi perusahaan ini adalah, belum adanya sikronisasi riwayat kondisi receiver. Berapa persediaan receiver, receiver rusak dan receiver baik. Dimana receiver ini digunakan sebagai alat menangkap sinyal bagi televise satelit. Receiver ini di pinjamkan pihak perusahaan kepada para pelanggan. Pendataan receiver selama ini dengan manual, sehingga apabila terjadi kerusakan maupun perbaikan pada receiver, riwayat kondisi receiver tidak dengan cepat diketahui hasilnya. Dari masalah ini penulis membuat rancang bangun sistem informasi riwayat perbaikan receiver dengan menggunakan metode waterfall. Dengan metode ini, penulis menganalisa kebutuhan sistem, mendesain tampilan web, merancang aplikasi dan menguji keberhasilan sistem. Hasilnya adalah, berupa sistem informasi berbasis web dimana data kerusakan receiver dapat dengan langsung di input dan diketahui permasalahan kerusakannya, diharapkan mempercepat laporan kondisi receiver, memudahkan pihak repair dalam menangani kerusakan receiver.
\end{abstract}

Kata Kunci : $\quad$ persediaan, Web, receiver, waterfall 


\section{PENDAHULUAN}

Sistem Informasi adalah kombinasi dari orang, data, hardware, software, jaringan, dan sumber data yang mengumpulkan, mengubah, dan menyebarkan informasi di dalam sebuah organisasi [1].

Persediaan adalah unsur utama dari banyak organisasi. Akibatnya, kontrol yang tepat adalah penting untuk profitabilitas organisasi dan pengembangan Masyarakat. Inventory Management System (IMS) memungkinkan visualisasi, spesifikasi, dan dokumentasi sistem intensif perangkat lunak. Perangkat lunak ini diuji untuk meningkatkan dan menyediakan penanganan yang tepat waktu dan efisien. Sistem manual memerlukan setiap hari penghitungan item dalam persediaan, kesalahan manusia sangat lazim selama penghitungan dan rekaman dan semua catatan manual persediaan akan rusak. [2]

Perkembangan teknologi yang sangat pesat di era globalisasi saat ini telah memberikan banyak manfaat dalam kemajaun diberbagai aspek sosial bersama seiring dengan adanya generasi baru sebagai penerus generasi yang lama. Beberapa cara adaptasi tersebut dapat diwujudkan dalam bentuk Sistem Informasi Inventory. Pencatatan pengolahan pada data barang sehingga dapat meningkatkan efektifitas perusahaan.
Memudahkan karyawan dalam melakukan bagian pengontrolan persediaan barang. 1 . Menyediakan informasi-informasi yang cepat, tepat dan akurat mengenai data maupun laporan. 2. Memudahkan proses di penyampaiannya laporan ke kantor pusat. [3] Website disebut juga site, situs, situs web, atau juga portal. Merupakan suatu kumpulan halaman web yang berhubungan antara satu dengan yang lainnya, halaman pertama sebuah website adalah home page, sedangkan halaman demi halamannya secara mandiri disebut web page, dengan kata lain website adalah situs yang dapat diakses dan dilihat oleh para pengguna internet diseluruh dunia. Website adalah situs yang dapat diakses dan dilihat oleh para pengguna internet, pengguna internet semakin hari semakin banyak, sehingga hal ini adalah potensi pasar yang berkembang terus. [4]

Pada penelitian yang berjudul Rancang Bangun Sistem Informasi Persediaan Barang Berbasis Web Dengan Metode Fast (Framework For the Applications), dijelaskan bahwa perusahaan yang bergerak dibidang jasa internet dan penyedia sparepart jaringan. Sistem informasi persediaan barang yang ada masih dilakukan dengan cara manual, mulai dari pencatatan barang masuk, permintaan barang dari bagian sales, proses barang 
keluar oleh bagian gudang sampai kepada pembuatan laporan, sehingga memungkinkan pada saat proses berlangsung terjadi kesalahan dalam pencarian data-data yang di perlukan. Solusi terbaik untuk memecahkan permasalahanpermasalahan yang ada adalah dengan membuat aplikasi persediaan barang berbasis web karena lebih baik dari pada pencatatan sistem yang manual. Rancang bangun sistem informasi persediaan barang berbasis website menggunakan metode pengembangan sistem yaitu FAST (Framework for the Application System Thinking) terdiri dari fase- fase scope Definition, Problem Analysis, Requirements Analysis, Logical Design dan Physical Design. Perancangan sistem informasinya menggunakan PHP dan HTML serta MySQL sebagai databasenya.[5]

Pada penelitian yang berjudul Sistem Informasi inventori Barang Menggunakan Metode Object Oriented di PT. Livaza Teknologi Indonesia Jakarta, dijelaskan bahwa sebuah perusahaan startup yang bergerak di bidang e-commerce khusus untuk furniture. Masalah yang sering terjadi di PT. Livaza Teknologi Indonesia adalah dalam mengelola inventory barang. Semua kegiatan tersebut masih dilakukan secara manual dan dalam penerimaan barang masuk dan barang keluar masih juga masih belum terkontrol. [6]

MNC Vision adalah sebuah stasiun televisi satelit berlangganan yang di selenggarakan oleh PT. MNC Vision (sebelumnya bernama PT MNC Sky Vision). Perusahaan yang didirikan pada tanggal 1988 ini memulai memasarkan produk jasanya pada awal tahun 1994 dan bertanggung jawab atas pemasaran program pengelolaan serta pelayanan kepada pelanggan. Dengan banyaknya peminjaman receiver kepada pelanggan, bagian repair kesulitan dalam mendata receiver yang sudah di perbaiki atau belum. Belum maksimalnya pendataan jumlah receiver, riwayat receiver yang digunakan pelanggan dan kondisinya. Hal ini menghambat kinerja repair untuk memperbaiki receiver. Dengan rancang bangun sistem informasi ini diharapkan petugas repair dapat langsung mengisi riwayat receiver secara online, sehingga keadaan dari receiver dapat diketahui statusnya. Apabila kondisi receiver masih fault maka dilanjutkan perbaikannya, dan apabila kondisi receiver sudah baik dapat di siapkan dan pergunakan kembali.

\section{METODE PENELITIAN}

Dalam penelitian ini, penulis menggunakan metode waterfall dalam 
pengembangan sistem yang terdiri dari empat tahapan seperti pada gambar :



Gambar 1. Model Waterfall

"Model waterfall sering juga disebut model sekuensial linier (sequential linear) atau alur hidup klasik (classic life cycle). Model air terjun menyediakan pendekatan alur hidup perangkat lunak secara sekuensial atau terurut dimulai dari analisis, desain, pengkodean, pengujian, dan tahap pendukung (support)”. [7] Berikut adalah tahapan dalam model waterfall :.
A. Analisis Kebutuhan Perangkat Lunak
B. Desain
C. Pengkodean
D. Pengujian

\section{HASIL DAN PEMBAHASAN}

\section{Analisis Sistem}

Dari permasalahan yang di uraikan di atas, penulis merancang sistem informasi meliputi halaman admin yang berisi proses pengolahan data receiver, proses receiver yang di terima, receiver keluar, laporan riwayat receiver,. Adapun untuk halaman karyawan ruang lingkupnya meliputi karyawan dapat melihat beranda, riwayat kondisi receiver, kontak kami, dan melakukan cara login terlebih dahulu dengan memasukan nik dan password.

\section{Desain}

Sistem informasi persediaan barang berjalan pada jaringan internet . dan desain yang akan di rancang untuk pemecahan masalahnya adalah :

Halaman Karyawan :

A1. Karyawan harus melakukan login untuk memesan barang.

A2. Karyawan bisa melakukan pemesanan berdasarkan merk.

A3. Karyawan memilih barang yang akan di pesan, bisa mengecek terlebih dahulu detail produknya.

A4. Karyawan dapat mengecek status pemesanan barang.

A5. Karyawan dapat melihat daftar pesanan. A6. Karyawan bisa melakukan Logout. Halaman Administrasi:

B1. Admin dapat melakukan login sesuai dengan hak akses.

B2. Admin dapat mengelola data user

B3. Admin dapat mengelola data barang masuk. B4. Admin dapat mengelola data menu merk. B5. Admin dapat mengelola data pesanan

B6. Admin dapat melihat laporan barang masuk.

B7. Admin dapat melihat laporan barang keluar. B8. Admin dapat mengelola stok barang. 
B9. Admin dapat melihat data transaksi.

\section{Use Case Diagram}

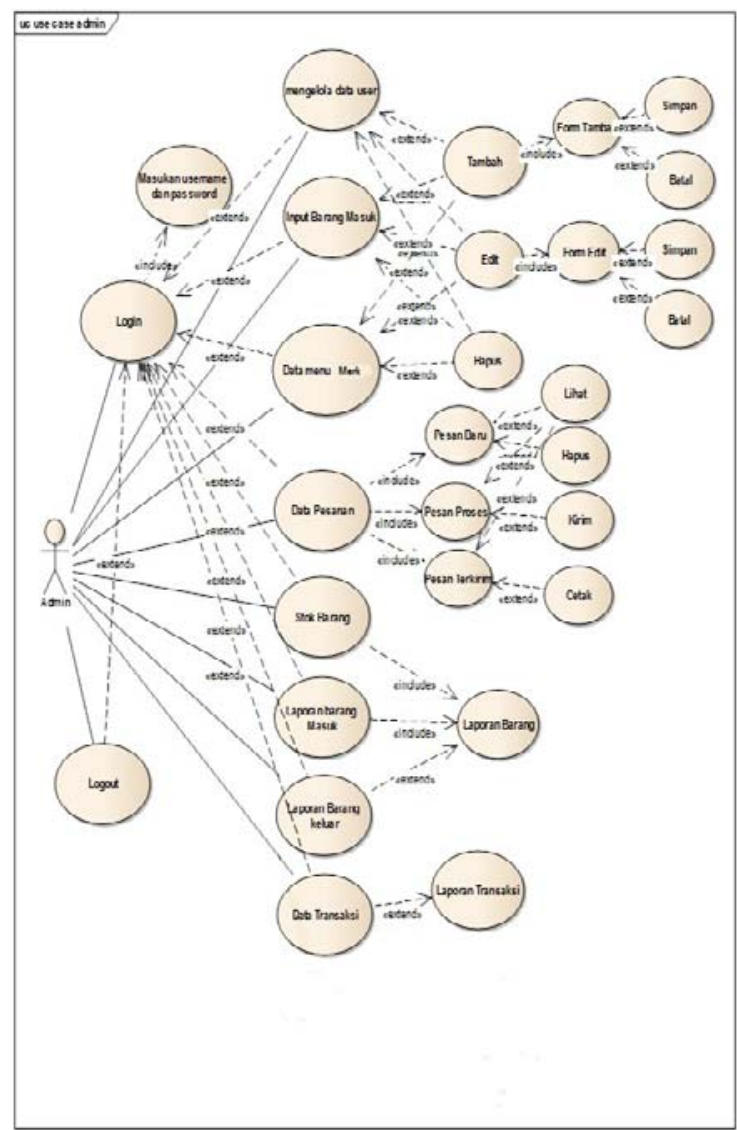

Gambar 2 Use Case Admin

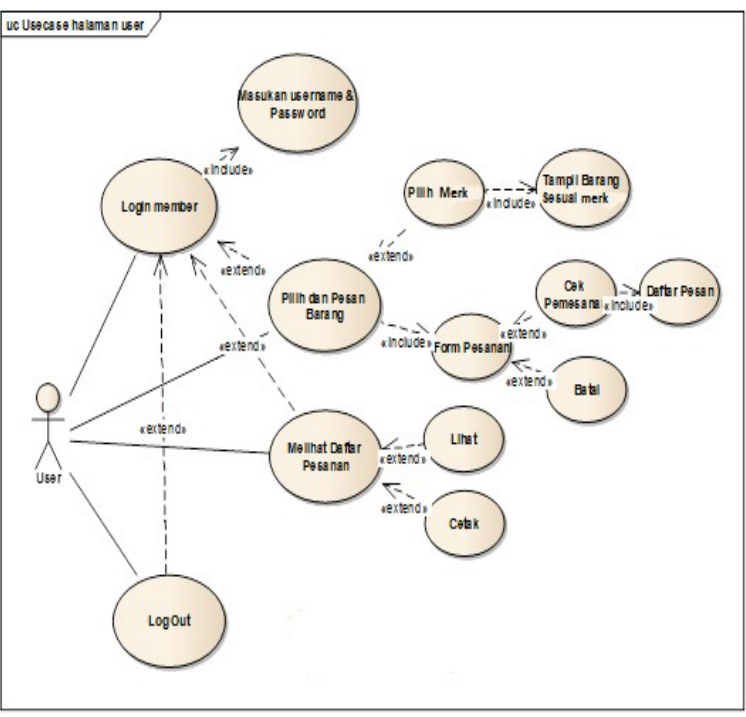

Gambar 3. Use Case Karyawan
Activity Diagram

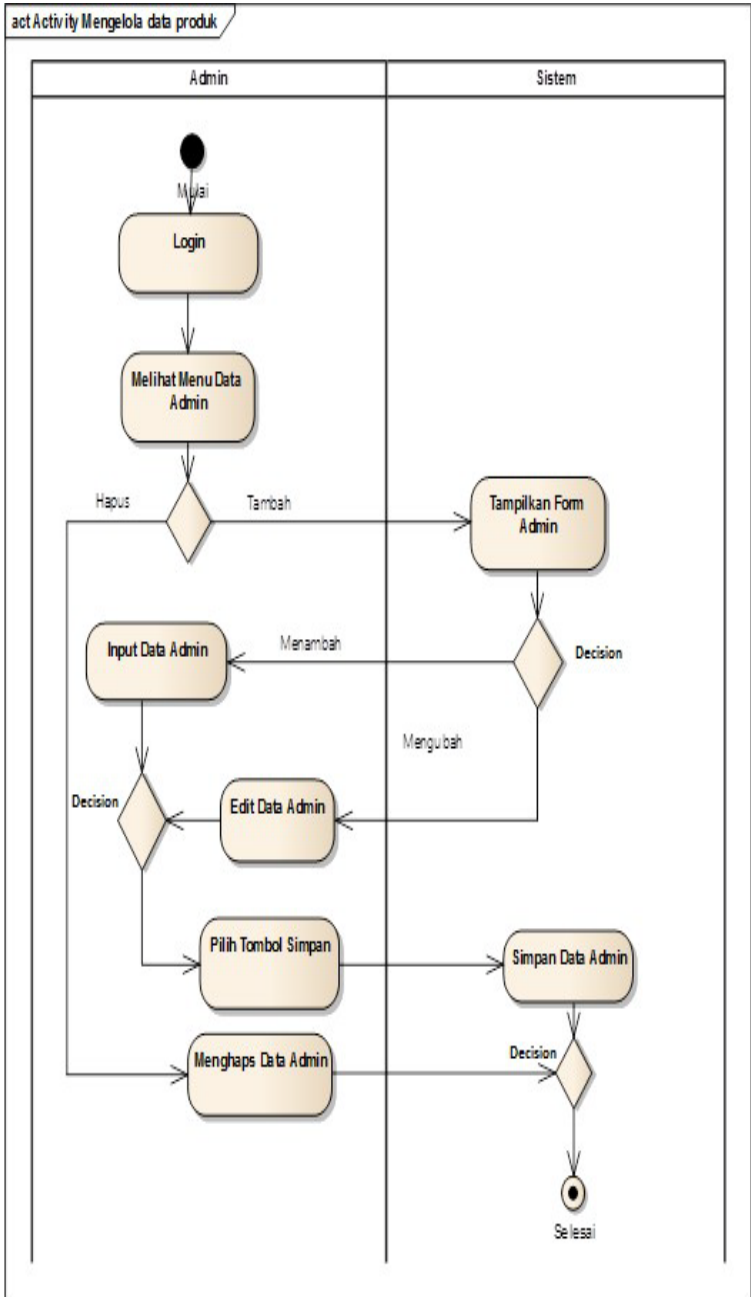

Gambar 4. Activity Diagram Data Admin 




Gambar 5. Activity Diagram Data Karyawan

\section{Desain Database}

Dalam perancangan sistem informasi riwayat receiver ini, terbentuk enam tabel yang saling berelasi, seperti rancangan entity relationship di bawah .

Entity Relationship Diagram

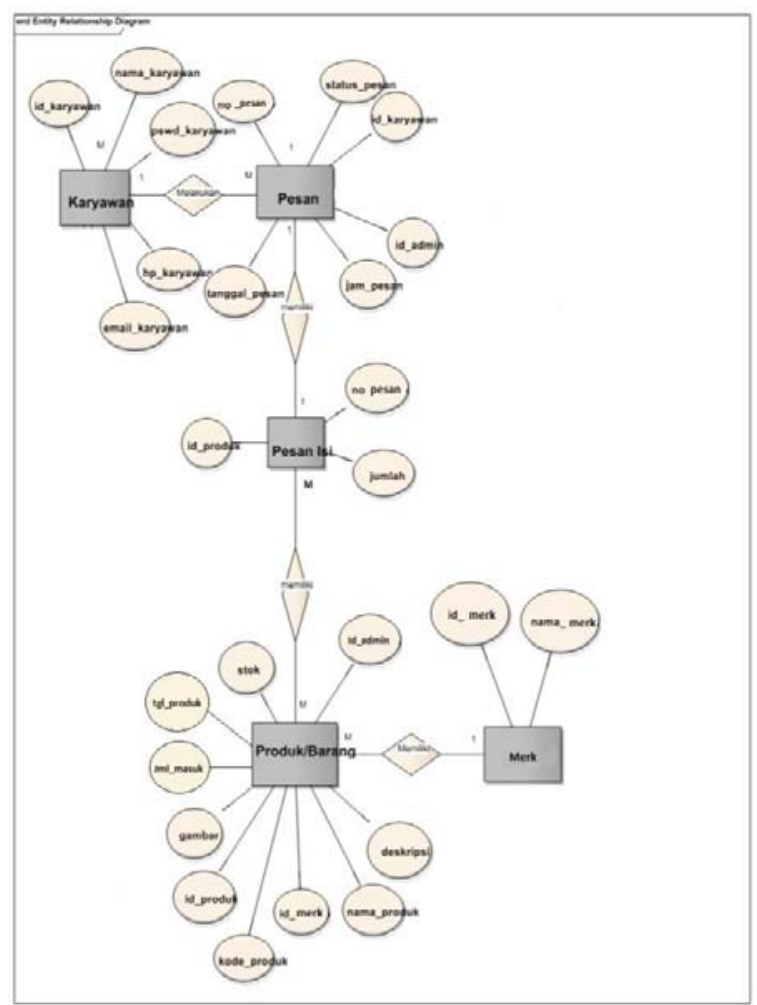

Gambar 6. ERD sistem informasi riwayat receiver

Logical Record Structure

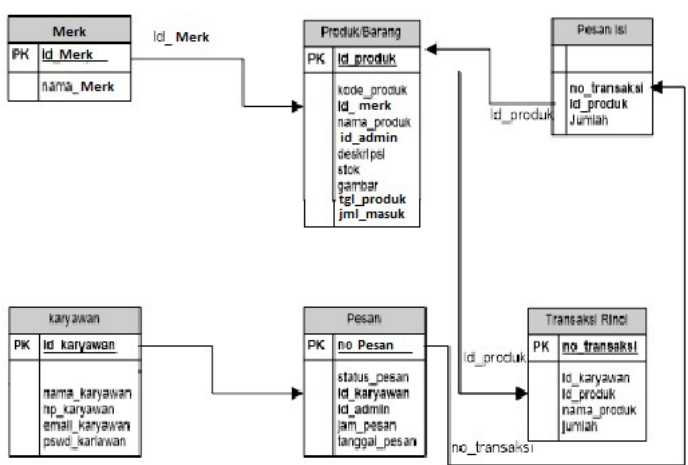

Gambar 7 LRS sistem informasi riwayat receiver 


\section{Rancangan Desain User Interface}

\section{Halaman Login Karyawan}

Pada halaman ini sebelum melakukan pengolahan data, karyawan diharuskan login terlebih dahulu dengan menginput user name dan password yang sudah terdaftar.

\section{LOGIN KARYAWAN}



M NC Vision


Filchr Posts

Gambar 7. Halaman login karyawan

setelah login sesuai, tampil beranda halaman karyawan yang berisi data pengolahan receiver
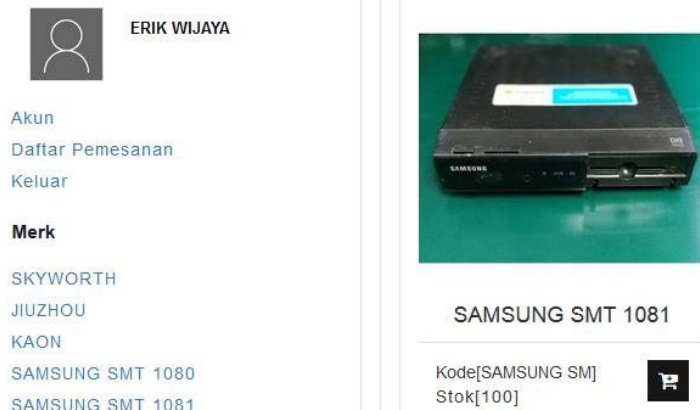

gambar 8. Halaman Beranda karyawan

2. Tampilan Pengolahan data produk Pada halaman ini user dapat mengolah data receiver, seperti menambah, menghapus dan Mengedit persediaan receiver

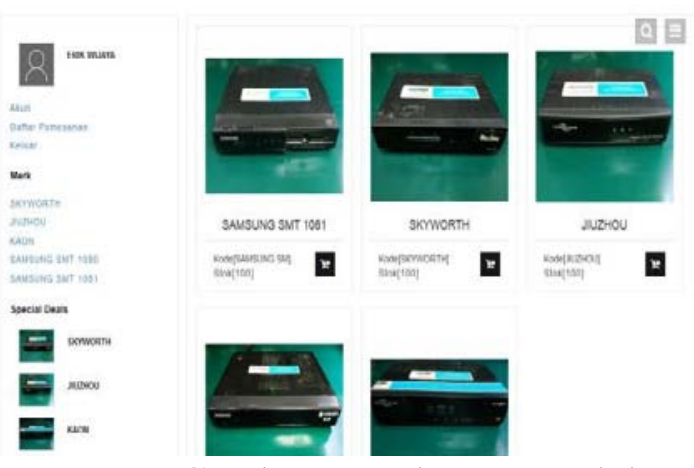

Gambar 9. Halaman Produk

untuk mengetahui detail produk halaman ini menjelaskan kelengkapan data tentang receiver.



Gambar 10. Halaman detail produk

\section{SIMPULAN}

Dengan menggunakan system informasi perbaikan receiver, memudahkan bagian repair dalam mengetahui kondisi receiver yang ada, bagian pemasangan dapat dengan mudah meminta receiver untuk digunakan, karena mengetahui stok receiver yang dalam kondisi bagus, sehingga dapat digunakan oleh konsumen dan dengan system informasi riwayat receiver berbasis web membantu admin atau logistic dalam control stok receiver kemudian .laporan kondisi receiver, dapat 
digunakan bagian manajemen dalam mengambil keputusan apakah menambah stok receiver atau tidak.

\section{UCAPAN TERIMA KASIH}

Terima kasih kepada MNC Vision yang sudah mengijinkan penulis untuk mengadakan riset. Dan terima kasih kepada semua pihak yang sudah membantu dalam penelitian ini.

\section{DAFTAR PUSTAKA}

[1] O’brien, James A; George M Marakas. 2011. Management Information Systems. The Mc-Graw-Hill Companies, Inc., USA.

[2] Metha S. Sagar, Prasad S Puranik, Satish B Sharma. A review on Inventory Management System for Improving efficiency of Project Development Cycle. Journal of Advanced Database Management \& System. 2016; vol 3; issue 3; 24-29

[3] Agusvianto, Hendra. 2017. Sistem Informasi Inventori Gudang Untuk Mengontrol Persediaan Barang Pada Gudang Studi Kasus: PT. Alaisys Sidoarjo. Journal Infomation Engineering and Educational Technology. JIEET: Volume 01
Nomor 012017.

[4] Abbas, Wahidin. 2013. Analisa Kepuasan

Mahasiswa Terhadap Website Universitas Negeri Yogyakarta (UNY). Prosiding SNST ke-4 Tahun 2013. Fakultas Teknik Univesitas Wahid Hasyim Semarang.

[5] Sari, Ani Oktarini dan Elan Nuari. Rancang Bangun Sistem Informasi Persediaan Barang Berbasis Web Dengan Metode Fast (Framework For The applications). Jurnal PILAR Nusa Mandiri Vol. 13, No.2 September 2017.

[6] Pahlevi, Omar. Astriana Mulyani dan Miftahul Khoir. 2018. Sistem Informasi Inventori Barang Menggunakan Metode Object Oriented di PT. Livaza Teknologi Indonesia Jakarta. Jurnal PRROSISKO Vol.5 No.1 Maret 2018.

[7] Sukamto dan M. Shalahuddin. 2015. Rekayasa perangkat Lunak. Bandung: INFORMATIKA. 